\title{
Perencanaan Estimasi Biaya K3 pada Proyek Pembangunan Kantor di Surabaya
}

\author{
Syaiful Anam ${ }^{1}$, Jenny Caroline ${ }^{2}$ \\ ${ }^{12}$ Program Studi Teknik Sipil, Fakultas Teknik Sipil dan Perencanaan, Institut Teknologi Adhi Tama Surabaya \\ Email: ${ }^{\text {syaifullanam3@gmail.com }}$
}

\begin{abstract}
Every construction work must have a big influence on work accidents. Occupational safety and health (K3) issues in construction services in general are often ignored. This shows the number of work accidents in this sector. Facts in the field of occupational safety and health (K3) implementation are still rarely done, because it only takes away time, first, it costs quite a lot for K3 needs. Therefore, this research will examine the planning of the Estimated Cost of Risk Prevention and OHS Supervision Costs in Office Construction Projects in Surabaya. The method used is making direct observations in the field, identifying accidents in the field, analyzing each sub-job in fulfilling $K 3$ needs, interviews, officers and taking documentation in the field. From this research obtained for the cost (K3) Rp. 51,975,000, - and for the contract fee is Rp. 3,250,336,000, - so the percentage is $1.62 \%$. The K3 needs evaluation plan is carried out using SNI and ANSI standards. The conclusion that can be drawn is that the OSH costs do not have a major effect on the overall project costs if calculated in detail, precisely with the K3 financing calculations it will be younger for companies to see the OHS costs that will be used for the Kalidami office building construction project in Surabaya.
\end{abstract}

Keywords: OHS, Costs, Construction, Estimates, Workers.

\begin{abstract}
Abstrak
Setiap pekerjaan konstruksi pasti memiliki pengaruh yang besar terhadap kecelakaan kerja. Permasalahan keselamatan dan kesehatan kerja (K3) pada jasa konstruksi secara umum di Indonesia masih sering tidak dihiraukan. Hal ini menunjukkan dengan masih tinggi angka kecelakaan kerja pada sektor ini. Fakta dilapangan pelaksanaan keselamatan dan kesehatan kerja (K3) masih jarang dilakukan, karena dianggap hanya membuang waktu saja, terlebih lagi mengeluarkan biaya yang cukup besar untuk kebutuhan K3. Oleh karena itu pada penelitian ini akan diteliti terkait perencanaan estimasi biaya K3 pada proyek pembangunan kantor di Surabaya. Metode yang digunakan yaitu melakukan pengamatan langsung di lapangan, Identifikasi risiko kecelakaan di lapangan, Mengurai setiap sub pekerjaan dalam pemenuhan kebutuhan K3, Wawancara, dan pengambilan dokumentasi di lapangan. Dari penelitian ini diperoleh untuk biaya K3 sebesar Rp Rp. 51.975.000,- dan untuk biaya Kontrak proyek adalah Rp. 3.250.336.000,- jadi untuk nilai prosentasinya adalah 1,62 \%. Dalam evaluasi rencana kebutuhan K3 dilakukan menggunakan standar peraturan K3 dari PUPR. Kesimpulan yang dapat diambil bahwasannya biaya K3 dapat di hitung secara terperinci, hasil dengan adanya perhitungan pembiayaan K3 akan lebih mudah bagi perusahaan untuk mengetahui biaya K3 yang akan dipakai untuk proyek pembangunan gedung kantor kalidami di Surabaya.
\end{abstract}

Kata Kunci : Biaya K3, Konstruksi, Estimasi, Pekerja.

\section{Pendahuluan}

Proyek Konstruksi di Indonesia memiliki resiko tinggi, karena angka kecelakaan kerja terbilang cukup tinggi [1]. Dampak dari kecelakaan proyek konstruksi tersebut dapat menyebabkan terhambatnya jalannya pelaksanaan pekerjaan proyek, serta dapat mengalami kerugian bagi perusahaan kontraktor dalam pembengkakan biaya penanganan kecelakaan tersebut. Salah satu proyek bangunan gedung kantor yang memiliki tingkat risiko yang tinggi adalah proyek di Jl. Kalidami, kota Surabaya. Di proyek ini banyak terjadi kecelakaan kerja, seperti pekerja yang jatuh dari bangunan lantai dua karena 
kurangnya rambu rambu pengaman serta tergelincirnya pekerja karena tidak menggunakan APD yang lengkap, hal ini tentunya sangat merugikan.

Bagi pihak jasa kontraktor maupun para pekerjanya. Dalam mengurangi permasalahan risiko kecelakaan pada pekerja bisa dikendalikan dengan penerapan Sistem manajemen K3 dalam penerapannya perlu adanya anggaran biaya kebutuhan K3 pada proyek konstruksi. Dalam mendukung perencanaan pembiayaan K3 dalam hal konstruksi pemerintah telah mengeluarkan peraturan sistem Manajemen Keselamatan dan Kesehatan Kerja (SMK3) diamanatkan melalui PP 50/2012 tentang kebijakan dalam pelaksanaan sistem manajemen K3 (SMK3). Sementara itu pedoman lain dalam pekerjaan konstruksi telah menerbitkan Peraturan SE Menteri PUPR Nomor 5 Tahun 2014 yang kemudian diperbarui dan disahkan menjadi putusan Menteri Pekerjaan Umum Sesuai SE Menteri PUPR 66/2015. Peraturan ini mengatur tentang tata cara melaksanakan kegiatan K3 dan tata cara pengalokasian biaya kebutuhan SMK3 oleh Pengguna Jasa. Jadi dengan peraturan tersebut tata cara pelaksanaan K3 dan komponen-komponen biaya kebutuhan K3 yang harus direncanakan dapat dilaksanakan dengan baik oleh pengguna jasa konstruksi [2]. Keselamatan dan Kesehatan Kerja (K3) sangat penting diterapkan pelaksanaan proyek konstruksi, agar terciptanya lingkungan yang aman dan keselamatan kerja [3].

Berdasarkan permasalahan diatas dapat disimpulkan bahwa perlu adanya penerapan pengalokasian anggaran SMK3 dalam nilai kontrak konstruksi secara tersendiri dari biaya umum lainnya, yaitu sebagai suatu kebutuhan biaya tersendiri dalam kontrak konstruksi. Nilai kebutuhan biaya tersendiri tersebut dimaksudkan agar pengalokasian anggaran SMK3 bisa transparan dan sesuai dengan alokasi kebutuhan pada proyek tersebut. Melihat permasalahan diatas, maka dibuat penelitian ini yang berjudul "Perencanaan Estimasi Biaya K3 Pada Proyek Pembangunan Kantor di Surabaya"

\section{Metode}

Metode yang digunakan adalah dengan menentukan breakdown pekerjaan - Jumlah tenaga kerja - risiko kecelakaan kerja - kebutuhan K3, dengan metode tersebut dapat diambil ketentuan terhadap jumlah kebutuhan K3 dari setiap pekerjaan.

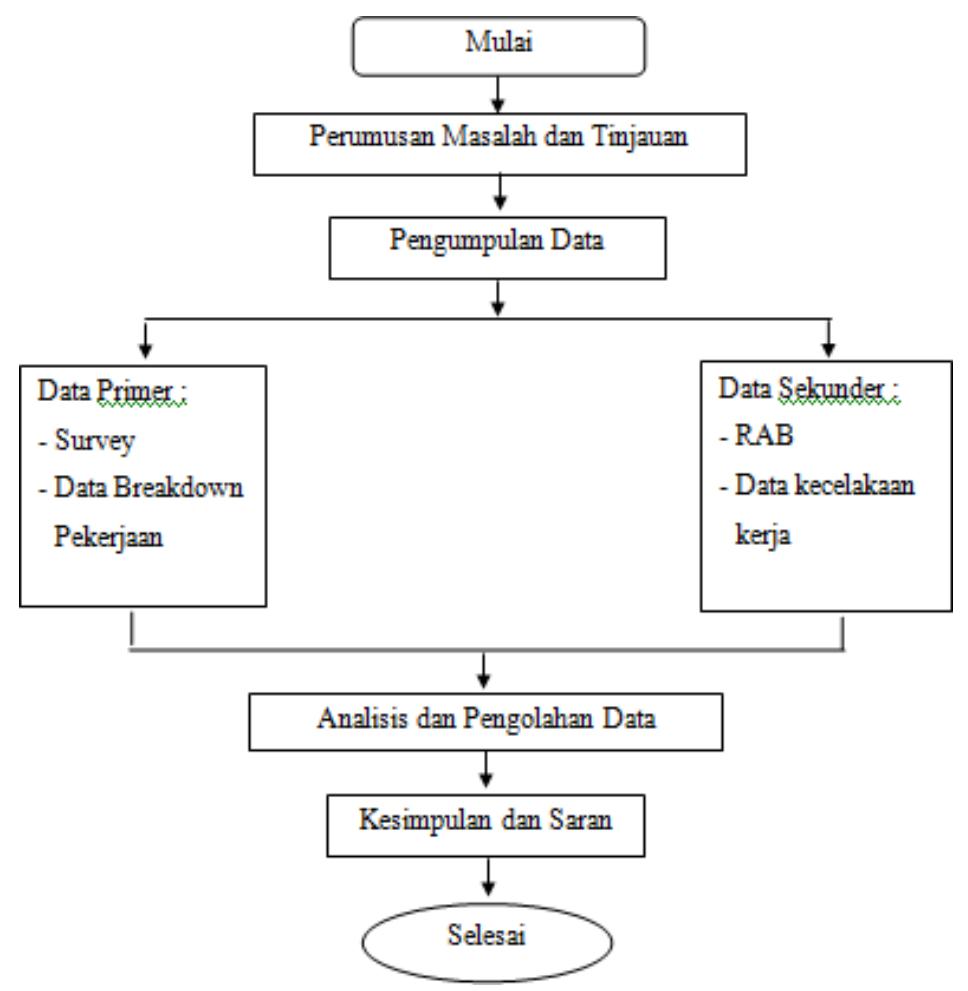

Gambar 1. Contoh penggunaan Diagram untuk pembuatan flowcart. 


\section{Hasil dan Pembahasan}

\subsection{Komponen Biaya K3 menurut Permen PUPR [2] Komponen Biaya Deskripsi :}

- Penyiapan RK3K Pembuatan Manual, Prosedure, Instruksi Kerja, Izin Kerja, Identitas pekerja dan tamu.

- Sosialisasi dan Promo K3 Induksi K3/Pengarahan K3/Safety Talk/toobox meeting pelatihan dan stimulasi K3, Banner, Spanduk dan Poster dan media promosi K3, Papan informasi dan Statistik K3

- Alat Pelindung Kerja Jaring Pengaman, Tali Keselamatan, Penahan Jatuh, Pagar Sementara, dan Pembatas Proyek.

- $\quad$ Alat Pelindung Diri Helm, Sepatu Safety, Kaca Mata Safety, Sarung Tangan, Full Body Harness, Alat Bantu Pernapasan, Jaket Pelampung

- Asuransi dan Perizinan Premi Asuransi, Surat Ijin Alat, Surat Ijin Operator

- Personil K3 Manager K3, Supervisor K3, Petugas Tanggap Darurat, Petugas Medis

- Fasilitas Kesehatan Peralatan P3K, Ruang P3K

- Rambu Petunjuk, Larangan, Peringantan, Kewajiban, Informasi, Rambu-rambu pekerjaan, Rambu - Rambu Lalu Lintas.

- Lain-Lain Terkait Pengndalian Risiko Peralatan Pemadam Kebakaran, Peralatan Tanggap Darurat, Program Audit Internal dalam pelaporan kecelakaan.

\subsection{Hasil Penelitian}

Hasil laporan tersebut menunjukkan banyak kecelakaan pada pekerjaan struktur yang mengalami empat insiden kecelakan yaitu pada saat Pekerjaan Pembesian dan pekerjaan pengecoran Kolom dan Plat Lantai, dilanjut pada pekerjaan arsitektur dengan dua insiden kecelakaan yaitu pada saat pekerjaan pemasangan bata dan pekerjaan lantai keramik, dan pekerjaan MEP dengan satu insiden kecelakaan yaitu pada saat pekerjaan Instalasi Listrik. Berikut Grafik dari Data Kecelakaan di proyek tersebut.

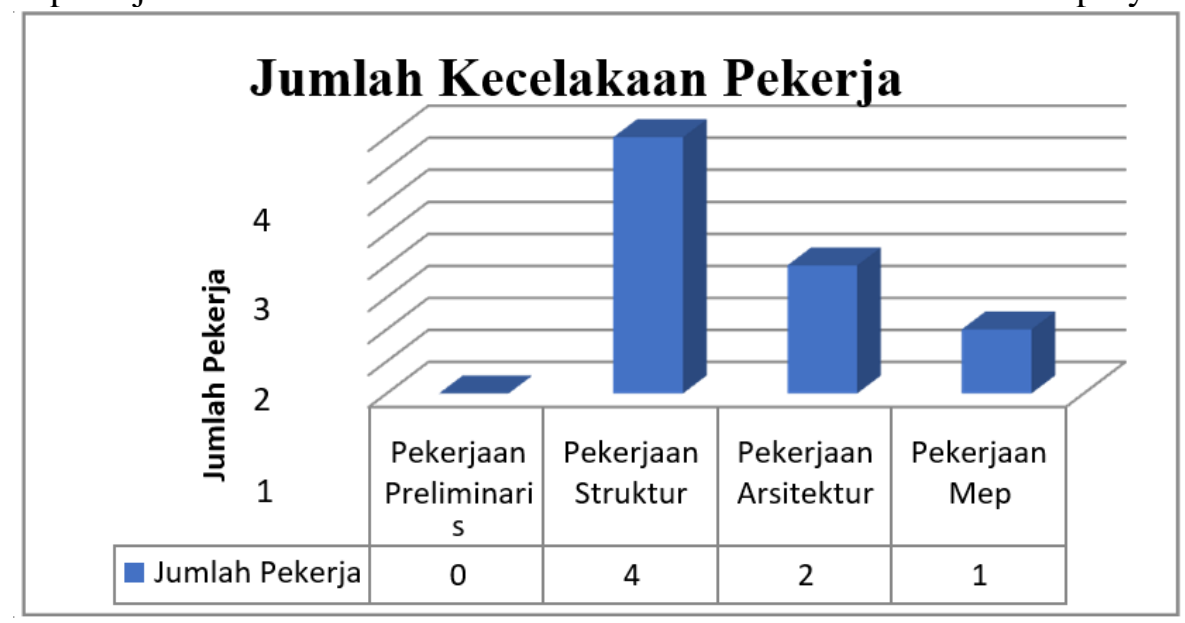

Gambar 2. Grafik Kecelakaan Kerja 
Tabel 1. Data Analisis Risiko dari beberapa pekerjaan

\begin{tabular}{|c|c|c|c|c|}
\hline No. & $\begin{array}{l}\text { Jenis Type } \\
\text { Pekerjaan }\end{array}$ & $\begin{array}{c}\text { Identifikasi } \\
\text { Bahaya }\end{array}$ & Tingkat Kecelakaan & Pencegahan Risiko \\
\hline \multirow[t]{2}{*}{1} & \multirow{2}{*}{$\begin{array}{c}\text { Pekerjaan } \\
\text { Pasangan Batu }\end{array}$} & $\begin{array}{l}\text { a. Tertimpa Batu } \\
\text { Belah }\end{array}$ & $\begin{array}{c}\text { Ringan/Sedang/ } \\
\text { Berat }\end{array}$ & $\begin{array}{c}\text { Helm Safety, Rompi, } \\
\text { Sepatu Safety, } \\
\text { Sarung Tangan }\end{array}$ \\
\hline & & $\begin{array}{l}\text { b. Material } \\
\text { tertabrak (Lalin) }\end{array}$ & Ringan/Sedang & $\begin{array}{c}\text { Jaring Pengaman, Tali } \\
\text { Keselamatan }\end{array}$ \\
\hline \multirow[b]{2}{*}{2} & \multirow[b]{2}{*}{ Urugan Tanah } & $\begin{array}{l}\text { a. Kendaraan } \\
\text { terperosok }\end{array}$ & Ringan/Sedang & $\begin{array}{c}\text { Pembatas Proyek, Tali } \\
\text { Keselamatan }\end{array}$ \\
\hline & & b. Tertimpa Urugan & Sedang/Berat & $\begin{array}{c}\text { Helm Safety, Rompi, Sepatu } \\
\text { Safety, Tali Keselamatan, Jaring } \\
\text { Pengaman, Penahan Jatuh }\end{array}$ \\
\hline \multirow{3}{*}{3} & \multirow{3}{*}{$\begin{array}{c}\text { Pekerjaan } \\
\text { Pasangan } \\
\text { dinding bata } \\
\text { berikut plester } \\
\text { aci }\end{array}$} & $\begin{array}{l}\text { a. Tertimpa } \\
\text { pasangan bata }\end{array}$ & $\begin{array}{c}\text { Ringan/Sedang/ } \\
\text { Berat } \\
\end{array}$ & $\begin{array}{l}\text { Helm Safety, Rompi, Sepatu } \\
\text { Safety, Sarung Tangan }\end{array}$ \\
\hline & & $\begin{array}{l}\text { b. Jatuh dari lantai } \\
\text { atas }\end{array}$ & $\begin{array}{c}\text { Ringan/Sedang/ } \\
\text { Berat }\end{array}$ & $\begin{array}{c}\text { Helm Safety, Rompi, Sepatu } \\
\text { Safety, Sarung Tangan, Tali } \\
\text { Keselamatan, Jaring Pengaman, } \\
\text { Penahan Jatuh }\end{array}$ \\
\hline & & $\begin{array}{l}\text { c. Tertimpa material } \\
\text { dari lantai atas }\end{array}$ & $\begin{array}{c}\text { Ringan/Sedang/ } \\
\text { Berat }\end{array}$ & $\begin{array}{l}\text { Helm Safety, Rompi, Sepatu } \\
\text { Safety, Sarung Tangan }\end{array}$ \\
\hline
\end{tabular}

Tabel 2. Data Breakdown Pekerjaan

\begin{tabular}{|c|c|c|c|c|}
\hline No & $\begin{array}{c}\text { Jenis } \\
\text { Pekerjaan }\end{array}$ & $\begin{array}{c}\text { Sub } \\
\text { Pekerjaan }\end{array}$ & Uraian Pekerjaan & $\begin{array}{c}\text { Kebutuhan K3 } \\
\text { Yang } \\
\text { Dibutuhkan }\end{array}$ \\
\hline \multirow{24}{*}{1} & \multirow{20}{*}{$\begin{array}{l}\text { Pekerjaan } \\
\text { Preliminaris }\end{array}$} & \multirow{20}{*}{$\begin{array}{l}\text { Pekerjaan } \\
\text { Persiapan }\end{array}$} & \multirow{5}{*}{ Pembersihan Lokasi } & Helm Safety \\
\hline & & & & Sarung Tangan \\
\hline & & & & Rompi \\
\hline & & & & Sepatu Safety \\
\hline & & & & Masker \\
\hline & & & \multirow{5}{*}{ Pembuatan Pagar Proyek } & Helm Safety \\
\hline & & & & Sarung Tangan \\
\hline & & & & Rompi \\
\hline & & & & Sepatu Safety \\
\hline & & & & Masker \\
\hline & & & \multirow{5}{*}{$\begin{array}{c}\text { Pengukuran \& Pasang } \\
\text { Bouwplank }\end{array}$} & Helm Safety \\
\hline & & & & Sarung Tangan \\
\hline & & & & Rompi \\
\hline & & & & Sepatu Safety \\
\hline & & & & Masker \\
\hline & & & \multirow{5}{*}{ Pembuatan Direksi keet } & Helm Safety \\
\hline & & & & Sarung Tangan \\
\hline & & & & Rompi \\
\hline & & & & Sepatu Safety \\
\hline & & & & Masker \\
\hline & & & \multirow{4}{*}{ Galian Tanah } & Helm Safety \\
\hline & & & & Sarung Tangan \\
\hline & & & & Rompi \\
\hline & & & & Sepatu Safety \\
\hline
\end{tabular}




\begin{tabular}{|c|c|c|c|c|}
\hline \multirow{6}{*}{2} & \multirow{6}{*}{$\begin{array}{l}\text { Pekerjaan } \\
\text { Struktur }\end{array}$} & \multirow{6}{*}{$\begin{array}{l}\text { Pekerjaan } \\
\text { Pondasi dan } \\
\text { Sloof }\end{array}$} & & Masker \\
\hline & & & \multirow{5}{*}{$\begin{array}{l}\text { Fabrikasi Tulangan } \\
\text { Pondasi Dan Sloof }\end{array}$} & Helm Safety \\
\hline & & & & Sarung Tangan \\
\hline & & & & Rompi \\
\hline & & & & Sepatu Safety \\
\hline & & & & Safety Glasses \\
\hline
\end{tabular}

\subsection{Jumlah pekerja}

Tenaga Kerja sangat berpengaruh cukup besar terhadap biaya maupun waktu penyelesaian dalam pekerjaan proyek, dan perlu diperhatikan karena manusia merupakan sumberdaya yang kompleks dan sulit diprediksi [4]. Produktivitas tenaga kerja juga sangat diperlukan dalam keberhasilan proyek [5]. Perencanaan Kebutuhan K3 didasarkan pada uraian pekerjaan diproyek tersebut hal ini berguna untuk mengetauhi estimasi kebutuhan K3 dari setiap pekerjaan. Dalam perencanaannya kebutuhan K3 dibagi menjadi dua perencanaan yaitu Kebutuhan Khusus K3 dan Kebutuhan Umum K3. Dalam penentuan terdapat beberapa indikator yakni :

Jenis Pekerjaan : hasil ini didapat dari jenis pekerjaan pada Time Schedule didalam dokumen proyek. Sub Pekerjaan : hasil ini didapat dari sub pekerjaan pada RAB.

Uraian Pekerjan : Hasil ini didasarkan pada analisisa di lapangan yang memerlukan penjelasan tertentu. Jumlah Pekerja : didapat dari

$\frac{\text { T.Volume Pekerjaan }}{\text { Waktu Pelaksanaan }(1 \text { Hari Kerja }=8 \mathrm{Jam})}=$ Jumlah Pekerja $/$ Hari

a. Pekerjaan Preliminaris

$$
\frac{89 \mathrm{~m}^{3}}{14 \text { Hari }}=6,36 \approx 6-8 \text { Pekerja/Hari }
$$

b. Pekerjaan Struktur

$$
\frac{4208,03 \mathrm{~m}^{3}}{154 \text { Hari }}=27,32 \approx 27-30 \text { Pekerja/Hari }
$$

c. Pekerjaan Arsitektur

$$
\frac{2758,27 \mathrm{~m}^{3}}{119 \text { Hari }}=23,18 \approx 23-25 \text { Pekerja } / \text { Hari }
$$

d. Pekerjaan MEP

$$
\frac{476,63 \mathrm{~m}^{3}}{47 \mathrm{Hari}}=10,14 \approx 10-12 \text { Pekerja/Hari }
$$

Tabel 3. Hasil Analisis Keseluruhan Estimasi Kebutuhan K3

\begin{tabular}{cll}
\hline No. & Uraian Kebutuhan & Biaya Kebutuhan \\
\hline 1 & Kebutuhan Khusus K3 & Rp. 25.630.000,- \\
\hline 2 & Kebutuhan Umum K3 & Rp. 26.840.000,- \\
\hline \multicolumn{2}{c}{ Total Estimasi Pendukung K3 } & Rp. 52.470.000,- \\
\hline
\end{tabular}


3.4. Prosentase Kebutuhan $K 3$

Dalam menetukan presentase biaya K3 dapat dibuat perhitungan sebagai berikut: Prosentase biaya K3 terhadap nilai Kontrak:

$\%$ Biaya $K 3=\frac{\text { Biaya Rab K3 }}{\text { Biaya Kontrak }} \times 100 \%$

$$
\% \text { Biaya } K 3=\frac{R p \cdot 52 \cdot 470 \cdot 000,-}{R p \cdot 3 \cdot 250 \cdot 336 \cdot 000,-} \times 100 \%=1,62 \%
$$

Jadi kebutuhan K3 untuk proyek pembangunan kantor, dengan pengambilan hasil perhitungan Biaya Kebutuhan K3 rencana sebesar Rp. 52.470.000, -, Jika diprosentasekan yang telah dihitung diatas sebesar $1,62 \%$.

\subsection{Analisis Pembahasan}

Hubungan terkait antara breakdown pekerjaan - Jumlah tenaga kerja - risiko kecelakaan kerja kebutuhan K3, sangat memiliki keterkaitan dalam penelitian ini, hal ini dimaksudkan dalam mencari kebutuhan K3 pada proyek tersebut dibutuhkan beberapa penjabaran dari setiap pekerjaan pada proyek tersebut,serta ditunjang dengan jumlah tenaga kerja, dan tingkat risiko yang ada diproyek tersebut, setelah hal tersebut diketahui maka akan ditemukan lah kebutuhan - kebutuhan K3 dari setiap pekerjaan pada proyek tersebut.

\section{Kesimpulan}

Kesimpulan yang didapat dari Perencanaan Estimasi Biaya K3 Pada Proyek Pembangunan Gedung Kantor Di Surabaya untuk Biaya yang dibutuhkan dalam Estimasi Biaya K3 Pada Proyek Pembangunan Gedung Kantor Di Surabaya adalah Rp. 52.470.000, -. Sedangkan hasil Nilai prosentase biaya K3 untuk proyek tersebut adalah 1,62 \%. Sedangkan Hasil kebutuhan K3 rencana pada Proyek Pembangunan Gedung Kantor di Surabaya yang disesuaikan dengan dasar perencanaan pada putusan Menteri Pekerjaan Umum Sesuai SE Menteri PUPR 66/2015 adalah sudah disesuaikan dengan peraturan tersebut dengan kebutuhan dilapangan.

\section{Referensi}

[1] I Wayan Jawat, dkk (2018), Estimasi biaya pencegahan dan pengawasan K3 pada proyek konstruksi bangunan gedung. Denpasar: Udayara Repository, UNUD, 2018.

[2] Peraturan Menteri Pekerjaan Umum Sesuai SE Menteri PUPR 66/2015.

[3] Christina, dkk.2018. Pengaruh Budaya Keselamatan dan Kesehatan Kerja (K3) Terhadap Kinerja Proyek Konstruksi.Jurnal Rekayasa Sipil.Vol 6(1) 83-95.

[4] Putrianti, P.R.2021.Evaluasi Jumlah Tenaga Kerja dalam Konstruksi Menghadapi Era New Normal.Jurnal Riset Rekayasa Teknik Sipil.Vol 4(2) 76-82.

[5] Jusmidah. 2016.Analisis Produktivitas Tenaga Kerja pada Proyek Pekerjaan Jembatan Amassangan.Jurnal Ilmiah Ilmu-Ilmu Teknik.Vol 1(1) 47-54. 